\title{
Mariátegui: socialismo y Buen Vivir
}

\section{Mariátegui: Socialism and Good Living}

\author{
Félix Pablo Friggeri*
}

ResUmen: el objetivo de este artíiculo es relacionar las propuestas de José Carlos Mariátegui y la del Buen Vivir en la búsqueda de la confluencia de caminos de superación del capitalismo en América Latina tanto en lo político como en lo epistémico. Se examinan las características del Socialismo Indoamericano de Mariátegui y su relación con la praxis indígena; el sujeto epistémico-político de esta construcción; la importancia de la subjetividad y la espiritualidad en estas propuestas y un esbozo de una agenda posible de diálogo entre el maxxismo y los movimientos indígenas en la línea de lo propuesto por el Amauta. Se establece un diálogo entre los elementos de un trabajo de campo realizado con el movimiento indígena ecuatoriano y material bibliográfico de Mariátegui y sus intérpretes. Se concluye resaltando la confluencia de ambas propuestas y su potencialidad para enriquecer el análisis de la realidad latinoamericana y alimentar propuestas políitcas liberadoras.

PALABRAS CLAVE: Mariátegui; Socialismo indoamericano; Buen Vivir; Búsqueda epistémico-política; Movimientos indígenas; marxismo.

ABSTRACT: The object of this work is to relate the proposals of José Carlos Mariátegui and that of Good Living in the search for the confluence of ways of overcoming capitalism in Latin America, both politically and epistemically. I present the characteristics of Mariátegui's Indo-American Socialism and its relationship with indigenous praxis; the epistemic-political subject of this construction; the importance of subjectivity and spirituality in these proposals and an outline of a possible agenda for dialogue between Marxism and indigenous movements along the lines proposed by Amauta. For the construction of the work I establish a dialogue between elements of a field work carried out with the Ecuadorian Indigenous Movement and bibliographic material of Mariátegui and his interpreters. I conclude by highlighting the confluence of both proposals and their potential to enrich the analysis of the Latin American reality and feed liberating political proposals.

KEYWORDS: Mariategui; Indo-American Socialism; Good living; Epistemic-political search; Indigenous movements; Marxism.

Recibido: 24 de octubre de 2019

Aceptado: 16 de mayo de 2020

Universidad Integración Latinoamericana, Brasil (fpfriggeri@hotmail.com). 


\section{INTRODUCCIÓN}

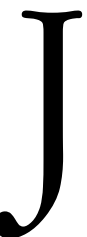

osé Carlos Mariátegui es, sobre todo, un revolucionario latinoamericano. Tuvo la enorme intuición de que para superar el capitalismo y el eurocentrismo, era clave hacer confluir los planteos que provenían desde fuera del continente - nuclearmente el marxismo- y la praxis comunitaria indígena. Transformó esta intuición en convicción de praxis política y de construcción de conocimiento. En el marco del comunismo internacional fue fuertemente relegado y condenado por "romántico y populista". Pero grandes autores latinoamericanos - algunos de los cuales son referencia clave de este trabajo-y las búsquedas de las luchas populares en nuestro continente volvieron a colocarlo como una brújula infaltable en la construcción de un camino y de un horizonte concreto, real y propio de superación del capitalismo en nuestra América Latina.

Por otro lado, aunque podamos sostener que la lucha indígena frente a la invasión colonial fue ininterrumpida, en las últimas décadas del siglo xx y comienzos del xxi hubo una confluencia de elementos que hizo que esta lucha emergiera y se expresara con una particular fuerza en lo que suele llamarse la propuesta del Buen Vivir. Estos elementos fueron, por un lado, la lucha contra el neoliberalismo y su violenta implementación en el continente y, por otro, el debate surgido en torno a los quinientos años de colonialidad. Ambos, confluyendo, fueron claves para la emergencia de los movimientos indígenas como sujeto histórico revolucionario.

Esta emergencia encontró un cauce importante en un hecho que ayudó a cristalizar estas propuestas: el surgimiento de gobiernos que se presentaron como opuestos al neoliberalismo y que inauguraron un proceso que - con ambigüedades y contradicciones, pero también con muchas realizaciones concretas- puede ser catalogado como el periodo de democratización más largo de nuestra región y, a nivel mundial, como el único proceso regional de contestación al neoliberalismo. En ese marco se crearon espacios para que la propuesta del Buen Vivir ingresara al debate político y epistémico de nuestra región y, en buena parte, lo trascendiera. 
En este trabajo expreso la confluencia entre ambas propuestas - la mariateguiana y la del Buen Vivir- porque tienen un enorme valor para la praxis política y para la construcción epistémica latinoamericana en búsqueda de horizontes propios de superación del capitalismo y de descolonización del conocimiento. Ambas propuestas tienen esa doble dimensión política y epistémica y su encuentro y diálogo las puede enriquecer mutuamente. Además, esta confluencia puede ayudar en un proceso de enraizamiento y recuperación del potencial revolucionario del marxismo en la región.

Para esto analizo la relación entre el socialismo indoamericano de Mariátegui y la propuesta del Buen Vivir en tres aspectos.

Primero, presento algunas características del socialismo indoamericano que propone Mariátegui y de la relación con las praxis indígenas que ha sido reivindicada y enriquecida desde el proceso de politización de lo étnico que los movimientos indígenas realizaron.

Luego, en un segundo punto, trato sobre el sujeto epistémico-político de esta construcción, que se relaciona con la pregunta de cuál es el "proletariado" latinoamericano en este doble aspecto. Unido a esto analizo la repercusión que este tema tiene para un replanteo "situado" del análisis de clase en nuestra región.

En un tercer punto trabajo sobre la importancia de la subjetividad y la espiritualidad en la tarea que este sujeto lleva adelante.

En el último punto esbozo una agenda de posibles tareas y de diálogo de saberes entre el marxismo y los movimientos indígenas en la línea de lo propuesto por el Amauta.

Para la construcción del trabajo establezco un diálogo entre elementos de un trabajo de campo realizado con el movimiento indígena ecuatoriano y material bibliográfico sobre Mariátegui y sobre la búsqueda de interpretar a Marx desde la realidad latinoamericana.

\section{SOCIALISMO INDO-AMERICANO}

La propuesta mariateguiana del socialismo indoamericano ha sido expuesta con gran riqueza por varios autores latinoamericanos. Junto a los textos 
de Mariátegui, me refereriré a ellos para hacer una breve presentación de algunos aspectos pensando, sobre todo, en su confluencia con el planteo del Buen Vivir. Por eso, esta sección pretende no una exposición exhaustiva sino establecer ejes de conexión entre las dos propuestas.

Comienzo con un párrafo que considero emblemático del proyecto socialista de Mariátegui, expresado en su artículo Aniversario y balance, tanto por su valor político como por su valor epistémico "No queremos, ciertamente, que el socialismo sea en América calco y copia. Debe ser creación heroica. Tenemos que dar vida, con nuestra propia realidad, en nuestro propio lenguaje, al socialismo indoamericano. He aquí una misión digna de una generación nueva" (Mariátegui 2005: 452).

Aquí encontramos los elementos nucleares de la originalidad del planteo mariateguiano, la cual es la llave para su potencialidad revolucionaria política y epistémica. El sentido de "creación heroica" hace referencia fundamentalmente a su raíz en la praxis de lucha popular, y centralmente en la indígena. El socialismo, para Mariátegui, "es ante todo una práctica que sólo se entiende desde el interior de la lucha de clases" (Flores 2008: T.V 357). La praxis es, para él, "la realidad última e irreductible de la existencia social y allí encuentra el fundamento de todo conocimiento y de toda posibilidad de transformar radicalmente la realidad social" (Germaná 1995: 183), por eso es principio clave tanto en lo epistémico como en lo político.

Esto lo acerca a la "filosofía de la praxis" y particularmente a Antonio Gramsci. Aunque las elaboraciones de Mariátegui y de Gramsci son independientes, existe entre ellos una "extraordinaria afinidad espiritual" que los une (Melis 1996: 27; Vanden y Becker 2013: 16; Terán 2008: 183).

Mariátegui gesta esta idea en la reflexión histórica sobre la experiencia de las mayorías populares y nuclearmente sobre las de los pueblos indígenas del Perú y de la región, es "la realidad indígena el núcleo central de su reflexión" (Melis 1996: 7). Por eso se basa en el "socialismo práctico" de las comunidades indígenas andinas, que "para el socialismo peruano" resulta clave: "este factor tiene que ser fundamental" (Mariátegui 2010b: 308). Ese socialismo, que sigue vivo y es parte de la estructura compleja del Perú de 
su época, es para él "un eventual sustento del futuro socialista" (Flores 2008: T. V 360-361). Así al organizar el Partido Socialista "su finalidad es la de construir el socialismo peruano a partir de las tradiciones comunitarias del mundo indígena" (Melis 1996: 24). Recordamos que en la propuesta socialista mariateguiana la medida de su validez es fundamentalmente práctica: depende "de la capacidad de encarnarse en las multitudes" (Flores 2008: T. V 392).

Es un tipo de socialismo que tiene su raíz en lo comunitario: "el comunismo agrario del ayllu' le sirve a Mariátegui como patrón de un socialismo no estatista... no admite las representaciones que reducen al socialismo a la propiedad estatal de los medios de producción. Las comunidades le suministraban un ejemplo de socialización concebida como propiedad social (colectiva) y usufructo de los medios de producción por parte de los productores directos y que además comprendía la socialización del poder (Mazzeo 2009: 96-97).

Para Mariátegui (2010b: 223) "las comunidades indígenas" constituyen "un elemento activo y vital de realizaciones socialistas". Esta calidad del ayllu como germen de una economía socialista autóctona es el punto principal de la crítica que le hace la ortodoxia comunista que lo acusa de "populismo" asimilándolo a la postura narodniki sobre la comunidad campesina rusa (Kaysel 2014: 232-233).

Otro elemento de la "creatividad heroica" que propone Mariátegui tiene que ver con el rechazo a entender el socialismo como una "concepción científica de la historia", como fruto de un "pensamiento racionalista" (Flores 2008: T. V 392): "no es, como algunos erróneamente suponen, un cuerpo de principios de consecuencias rígidas, iguales para todos los climas históricos y para todas las latitudes sociales" (Mariátegui 2010b: 140). Así evita un reduccionismo que deje afuera la práctica social de las mayorías populares (Germaná 1995: 183). Al contrario, él encuentra la posibilidad de cualificar la creación socialista - tanto en lo político como en lo epistémico- en "la reivindicación firme y positiva de las raíces, para utilizar una palabra que tiene en el Mariátegui maduro una frecuencia abrumadora" (Melis 1996: 15). Es una convocatoria a la creatividad: ya no 
se piensa en el socialismo como una planta foránea adaptada a la región, ${ }^{1}$ se piensa en raíces propias que crecen desde el subsuelo histórico, político y epistémico de América Latina y que el vínculo con ellas condiciona la posibilidad de crecimiento y fecundidad de la praxis revolucionaria socialista y de la construcción de un conocimiento concordante.

Antes de avanzar conviene plantear algunos elementos de la relación de Mariátegui con el marxismo, sin querer entrar en un análisis detallado del tema. Podríamos decir, por un lado, que esta actitud creativa y plural del Amauta no cabía en todos los marxismos existentes. Él mismo veía que "Marx no está presente, en espíritu, en todos sus supuestos discípulos y herederos. Los que lo han continuado no han sido los pedantes profesores tudescos de la teoría de la plusvalía, incapaces de agregar nada a la doctrina, dedicados sólo a limitarla, a estereotiparla" (Mariátegui 2005: 331).

Es muy significativo el carácter emblemático que le da a la figura de Georges Sorel en este sentido. Al enaltecerlo intenta reafirmar lo "esencial y sustantivo" de Marx en el carácter revolucionario y dinámico al que opone tendencias que estaban presentes en la interpretación del marxismo que le era contemporánea:

La verdadera revisión del marxismo, en el sentido de renovación y continuación de la obra de Marx, ha sido realizada, en la teoría y en la práctica, por otra categoría de intelectuales revolucionarios. Georges Sorel, en estudios que separan y distinguen lo que en Marx es esencial y sustantivo de lo que es formal y contingente, representó en los primeros decenios del siglo actual -más acaso que la reacción del sentimiento clasista de los sindicatos, contra la degeneración evolucionista y parlamentaria del socialismo- el retorno a la concepción dinámica y revolucionaria de Marx y su inserción en la nueva realidad intelectual y orgánica. A través de Sorel, el marxismo asimila los elementos y adquisiciones sustanciales de las corrientes filosóficas posteriores a Marx. Superando las bases racionalistas y positivistas del socialismo de su época, Sorel encuentra en Bergson y los pragmatistas ideas que vigorizan el pensamiento socialista, restituyéndolo a la misión revolucionaria de la cual lo había gradualmente alejado el aburguesamiento intelectual y espiritual de los partidos y de sus parlamen-

1 Mariátegui (2005: 95) en un artículo de 1918 había hecho esta comparación, pero fue cambiando esta postura posteriormente. 
tarios, que se satisfacían, en el campo filosófico, con el historicismo más chato y el evolucionismo más pávido (Mariátegui 2017: 28).

Teniendo en cuenta todo esto, si miramos hacia el planteo del Buen Vivir vemos que eminentemente proviene también de una praxis de lucha histórica, ancestral, milenaria y lo más interesante -y que destacaba Mariátegui-, es que esta praxis está viva y vigente aun cuando siglos de opresión la pueden haber lastimado. La definición que - cuando comenta al Amauta - da Mazzeo del concepto de "elementos de socialismo práctico" se acerca notablemente a las elaboraciones que expresan al Buen Vivir: "designa la realidad actuante de la comunidad campesina-indígena y de sus históricos lazos sociales, sus hábitos de cooperación y sus modos de relacionarse los seres humanos entre sí y con la naturaleza (componentes societarios y relaciones radicalmente nuevas de intercambio metabólico en la sociedad y de la sociedad con la naturaleza)" (Mazzeo 2009: 64-65).

La expresión "Buen Vivir" es la traducción castellana del principio cosmovisional indígena andino Sumak Kawsay, del idioma quechua. Una "definición" para ayudar en la comprensión de este principio puede ser esta: "Es una concepción andina ancestral de la vida, que se ha mantenido vigente en comunidades indígenas hasta la actualidad. Sumak significa lo ideal, lo hermoso, lo bueno, la realización; y Kawsay, es la vida, en referencia a una vida digna, en armonía y equilibrio con el universo y el ser humano. En síntesis, el Sumak Kawsay significa la plenitud de la vida" (Kowii 2014: 168).

Esta traducción se utilizó para la incorporación de este principio a la Constitución Ecuatoriana en 2008. En la Constitución Boliviana se usa la traducción "Vivir Bien" y se referencia en la expresión aymara "Suma Qamaña". Aunque se plantea que la traducción castellana tendría que indicar más bien "vida plena" o "vida hermosa" (Inuca 2017: 25). Ambos términos expresan básicamente una praxis ancestral y, a la vez, viva y existente que está basada en un sentido comunitario y en una búsqueda de armonía que liga a los seres humanos y a la naturaleza. "Vivir Bien es vivir en comunidad, en hermandad y especialmente en complementariedad. Es una vida comunal, armónica y autosuficiente. Vivir Bien significa comple- 
mentarnos y compartir sin competir, vivir en armonía entre las personas y con la naturaleza. Es la base para la defensa de la naturaleza, de la vida misma y de la humanidad toda" (CAOI 2010: 34).

El contenido de lo que expresan estos principios aparece en pueblos y naciones indígenas de toda América, de tal forma que ese contenido constituye una especie de denominador común y abre a la posibilidad de una expresión representativa del mundo indígena en América Latina. "Las muchas naciones indígenas originarias desde el norte hasta el sur del Abya Yala tenemos diversas formas de expresión cultural, pero todas emergen del mismo paradigma: concebimos la vida de forma comunitaria, no solo como relación social sino como profunda relación de vida" (CAOI 2010: 30).

$\mathrm{Al}$ ser un principio ancestral viene pasando por un proceso de construcción epistémica y política en la búsqueda de los movimientos indígenas de poder expresar sus propuestas e introducirlas en el debate político latinoamericano. Este proceso viene siendo expresado en el concepto de "politización de lo étnico". ${ }^{2}$ Siendo una propuesta vivida ancestral y actualmente en el mundo indígena - aún con heridas y dificultades-, también es propuesta al mundo como respuesta a la crisis civilizatoria capitalista a la que se llega por la explotación del hombre y la naturaleza. Como todo principio cosmovisional está ligado indisolublemente a otros principios y eso queda expresado tanto en la Constitución Ecuatoriana que incorpora los derechos de la Pachamama, como en la boliviana que incorpora otros principios tanto del mundo andino como del guaraní. Especialmente en la mayor parte de la dirigencia indígena aparece la conciencia de que estos principios cuestionan radicalmente al capitalismo y a la constitución colonial y racista del Estado-Nación. Por eso, entre otras consecuencias, ha sido planteado como un proyecto de superación del capitalismo (Llasag 2009) lo cual lo emparenta a otras luchas históricas latinoamericanas que se condensan muchas veces bajo el nombre de "socialismo".

2 Este concepto expresa el proceso de los movimientos indígenas por el cual organizaron y formularon sus propuestas políticas desde sus propias cosmovisiones superando las limitaciones de propuestas anteriores que acentuaban separada y unilateralmente la dimensión política o la dimensión cultural. 
Los dirigentes indígenas ecuatorianos me expresaban una clara conciencia de que ellos viven ancestralmente un socialismo propio. Blanca Chancoso, que dirigió la escuela de formación política de mujeres de la Confederación de Nacionalidades y Pueblos Indígenas del Ecuador (Conaie) y que tuviera una destacada actuación en el Foro Social Mundial, me decía: "Nosotros decimos: alguien que quiere el socialismo, alguien que quiere vivir una vida comunitaria, 'comunista' le llaman, nosotros ya lo vivimos, lo hemos vivido, y que posiblemente después nos vamos contagiando al otro lado, pero es factible retomarlo y vivirlo. No así los otros, porque no lo han vivido, por eso yo creo que se puede compartir una alternativa distinta" (Entrevista realizada por el autor, Quito 2009).

Humberto Cholango, quien fue presidente de la Central Regional Indígena Andina y de la Confederación Nacional, también decía: "Nosotros somos sociedades colectivas, naciones originarias que estamos presentes y que practicamos democracia, que practicamos por naturaleza, nuestro nacimiento es colectivo. Que a eso le llamen socialismo, le llamen comunismo, pero somos eso" (Entrevista realizada por el autor, Quito 2009).

Desde esta praxis, politizando lo étnico, se fue gestando también una irrupción epistémica de los movimientos indígenas como uno de los elementos nucleares de la descolonización en la construcción de conocimiento, constituyendo así una "ruptura epistemológica" (Macas 2014: 172).

\section{HACIA UN NUEVO PROLETARIADO LATINOAMERICANO}

Uno de los elementos fundamentales del planteo mariateguiano tiene que ver con el sujeto político que construye y protagoniza ese socialismo indoamericano, dicho de otro modo: la revisión situada en América Latina del problema del proletariado, del sujeto revolucionario tanto en lo político como en lo epistémico.

Su primer gran aporte es convertir en pregunta lo que aparecía como una certeza. No es automático que el sujeto político de la revolución, de la construcción del socialismo, sea el obrero industrial -y fundamentalmen- 
te urbano-. Hay que preguntarse quién es el proletariado en América Latina, hay que buscarlo. Esta "búsqueda del proletariado" que es "un problema, un interrogante más que una respuesta" implica "redefinir la hegemonía obrera" y encontrar en los pueblos indígenas "la fuente principal de la energía revolucionaria" (Flores 2008: T. V 371, 262), un componente clave del sujeto revolucionario (Tible 2009: 102).

Este es uno de los elementos con que Mariátegui ayuda a enriquecer el análisis de clase. Además propone una complejización del análisis social de manera que Aníbal Quijano (2014: 288) entiende que uno de sus grandes aportes está en haber gestado el embrión del planteo de la heterogeneidad histórico-estructural que va a ser tomado por la reflexión latinoamericana. Pero entiendo que su mayor riqueza consiste en encontrar el valor de alternativa y de base para un cambio revolucionario en aquel "sector" de América Latina que era entendido como arcaico y atrasado, calificativo que se ligaba a su base en relaciones sociales personales y familiares y en el trabajo colectivo (Stavenhagen 1996: 174) y juzgadas -por muchas de las versiones de las teorías de la modernización y del desarrollo- como elemento causante del subdesarrollo regional. Por todo esto la tendencia generalizada era trabajar para que en algún momento desaparezca:

Mariátegui convierte lo que desde el emplazamiento eurocéntrico infecto de positivismo aparecía como una "rémora", un elemento de "atraso", en "presuposición" para una "posición", en historia asumida, en autofundamento o, dicho de otro modo: en elemento plenamente funcional a la sociedad autoemancipada, la sociedad futura. Las supuestas taras se convierten en estímulo. Las clases "residuales" se convierten en sujeto histórico (Mazzeo 2009: 178).

Aquí me parece importante relacionar este planteo con el que hace Enrique Dussel en relación a la "exterioridad". Él sostiene que el pueblo es, "en tanto oprimido" parte del sistema (Dussel 1986: 95), pero que tiene una capacidad creativa, alternativa y revolucionaria porque sostiene una "positiva exterioridad cultural" al sistema (Dussel 1977: 69). Si en el campo popular se puede hablar de un colectivo que puede ser referencia 
de "exterioridad cultural" al capitalismo, sin duda el mundo indígena ocupa el primer lugar.

En el planteo indígena hay un cuestionamiento a los saberes dominantes que se hace con una potencialidad extraordinaria justamente por esta condición de "exterioridad". Esos saberes dominantes que son objeto de contestación son, primero y fundamentalmente, los que están ligados a la reproducción capitalista y a la conservación del statu quo, principalmente los que acompañan intelectualmente la dominación y explotación neoliberal. Pero es cierto que también hay saberes occidentalizados de "izquierda" que intentaron ejercer una dominación sobre el mundo indígena y, lamentablemente, compartieron - y muchas veces compartenuna actitud de desprecio y superioridad frente a los saberes populares, entre ellos los indígenas.

El reconocimiento de la riqueza del mundo indígena en sus sabidurías de lucha fortalece la necesidad de que los que se proponen construir alternativas políticas y epistémicas superadoras del capitalismo abandonen cualquier lugar de dominación. Invita a abandonar posturas contaminadas del eurocentrismo que contiene esta actitud y a colocarse en actitud de "discipulado" frente a las sabidurías que provienen de las luchas populares, entre ellas nuclearmente las indígenas. Así, finalmente, invita a que se instrumente un profundo y desafiante diálogo de saberes.

El reconocimiento y la opción ético-política por un lugar epistémico desde donde producir el conocimiento es algo clave. El "lugar" es clave porque da las "cercanías" y las "lejanías" tanto en lo epistémico como en lo político. La actitud de Mariátegui es ejemplar en este sentido.

El planteo indígena también pone en cuestión un tipo de análisis de clase "heredado" y, en general, sin negarlo lo incluye en un proceso descolonizador. Al incorporarse el componente étnico se posibilita construir una enorme potencialidad para enriquecer este análisis, latinoamericanizándolo, dotándolo de una necesaria historización situada y potencializando la motricidad de la lucha de clases con un elemento que estaba ausente o por lo menos minimizado. 
Aquí me parece importante incorporar el concepto de "racismo de clase" en diálogo con el planteo de Colonialidad del Poder (Quijano 2000), para ayudar en este enriquecimiento. Este aporte puede servir no solamente para América Latina sino para todo el Sur Político - marcado por la colonialidad-, pero también puede servir para analizar las realidades contemporáneas en la Europa "avanzada" y en Norteamérica donde este racismo de clase - vía clase trabajadora migrante sobre todo- hoy también es una realidad.

\section{UNA INTERSUBJETIVIDAD}

Y ESPIRITUALIDAD REVOLUCIONARIA

Otro de los grandes aportes enriquecedores de Mariátegui en su planteo del socialismo, es la presencia valorada y constante de la subjetividad, la espiritualidad, la ética. El cambio en las relaciones sociales, con un lugar destacado de lo intersubjetivo, es una de las claves del planteo socialista mariateguiano:

pensaba en la sociedad socialista como aquella donde se constituían nuevos patrones culturales y orientaciones valorativas, cognoscitivas y motivacionales; una sociedad con un nuevo sentido de la vida, en completa oposición al que tenía la sociedad capitalista. El socialismo no era, pues, la continuación y el coronamiento de la sociedad del trabajo que había surgido con el capitalismo; lo concebía como otra forma de racionalidad, no centrada en la técnica y en el beneficio sino en la solidaridad y en la comunicación. Más aún, pienso que esta idea constituía el substrato más profundo de sus reflexiones y el elemento que suponía, abarcaba y daba sentido a los otros aspectos del socialismo: la socialización de los recursos de producción y la socialización del poder político. Se trata, por lo tanto, del núcleo alrededor del cual se articula el pensamiento de José Carlos Mariátegui (Germaná 1995: 171).

Es que la praxis de lucha popular que está como punto de partida político y epistémico abarca las manifestaciones organizativas que tienen 
expresa relevancia política, pero también abarca la praxis de la lucha cotidiana por la vida. Mariátegui aborda también la proyección política de la cotidianeidad (Melis 2013). Mazzeo también destaca "el interés de Mariátegui por lo cotidiano (el espacio de reproducción) como locus de la dominación y la explotación y también de la resistencia y la lucha por un orden alternativo" (2009: 94).

Mariátegui expresa este sentido distinto de las relaciones sociales en el concepto de "alma matinal". Aquí hay una conexión muy interesante y que merece un estudio aparte, en la relación entre Mariátegui, su obra y sus continuadores y el contacto del Che Guevara con el marxismo (Vanden y Becker 2013: 14) y muy especialmente con algunos temas: como el planteo del Hombre Nuevo y los estímulos morales de la producción. Al presentar este concepto, Mariátegui (2010a: 38) sostiene que "el hombre nuevo es el hombre matinal".

El papel revolucionario del Mito es también "un componente esencial de la concepción mariateguiana" (Melis 1976: 26). Su importancia está en las potencialidades que contiene: 1) la autorrealización humana ("satisfacer toda la necesidad de infinito que hay en el hombre [.. . ] llenar su yo profundo"); 2) el impulso a la movilización ("el mito mueve al hombre en la historia", "la historia la hacen los hombres poseídos e iluminados por una creencia superior, por una esperanza super-humana"); 3) como dador de sentido histórico ("sin un mito la existencia del hombre no tiene ningún sentido histórico"); 4) su fecundidad ("sin un mito los hombres no pueden vivir fecundamente"); 5 ) la diferencia frente a la burguesía ("Lo que más neta y claramente diferencia en esta época a la burguesía y al proletariado es el mito. La burguesía no tiene ya mito alguno. [...] El proletariado tiene un mito: la revolución social."); 6) la reanimación de los "pueblos en colapso". El pueblo "se mueve con una fe vehemente y activa" hacia él y la pasión y la voluntad son la fuerza de los revolucionarios, una "fuerza religiosa, mística, espiritual". Esto caracteriza al socialismo que propone Mariátegui. Este "camino de la fe, lo encontrarán las multitudes" que entienden esto como "la lucha final" (Mariátegui 2010a: 47-56). 
Existe, también, un planteo sobre el espacio-temporalidad que destaca especialmente Oscar Terán. Él sostiene que Mariátegui encontró

en el antiprogresismo soreliano un modo de desquiciar la temporalidad liberal (acumulativa, cuantitativa, homogénea) y de eludir el etapismo segundo internacionalista. Entonces la revolución podía devenir el acontecimiento que horadaba el tiempo uniforme y comunicar un futuro utópico (el socialismo) con un pasado mítico (el mundo indígena), mediante el gesto que descoyuntaba la temporalidad del progreso acumulativo (Terán 2008: 181).

Este autor también destaca un "movimiento de ir hacia atrás para saltar hacia adelante, como capacidad prodigiosa de un tipo de marginalidad" desde el cual Mariátegui piensa la revolución: "un retorno hacia la comunidad indígena y el incario para saltar al socialismo" (Terán 2008: 186). Aquí está una clave de descolonización: la reivindicación revolucionaria de la tradición popular indígena.

El pasado incaico ha entrado en nuestra historia, reivindicado no por los tradicionalistas sino por los revolucionarios. En esto consiste la derrota del colonialismo, sobreviviente aún, en parte, como estado social -feudalismo, gamonalismo-, pero batido para siempre como espíritu. La revolución ha reivindicado nuestra más antigua tradición (Mariátegui 2010b: 343-344).

También en el planteo del Buen Vivir es otro sentido de la vida lo que se ofrece, no solamente otro orden económico y político. En él "emerge un nuevo horizonte histórico de sentido, alternativo al que tiene procedencia y carácter europeo y eurocentrista una subversión latinoamericana respecto del modo eurocéntrico de producción de intersubjetividad" (Quijano 2014: 11).

La propuesta descolonizadora en América Latina y el planteo del Buen Vivir constituyen, para el pensamiento de Aníbal Quijano, una particularidad latinoamericana: 
frente a la "posmodernidad" y a la posible "des/modernidad" sin "des/ colonialidad", es el primer espacio/tiempo histórico no solamente no eurocéntrico, sino alternativo: "Des/colonialidad del Poder y Buen Vivir". Entonces, ese lugar epistemológico que es América Latina tiene una especificidad: lo indígena, porque "el horizonte histórico de sentido alternativo al eurocéntrico y eurocentrista, está siendo producido, ante todo, desde esa específica 'indigenidad”' (Quijano 2014: 18).

¿Sería el Buen Vivir el mito que moviliza a los movimientos indígenas en estos tiempos? Es una cuestión para el debate pero no parece lejos de lo que planteara Mariátegui.

El planteo indígena del espacio-temporalidad también está expuesto en términos muy cercanos a la postura mariateguiana. Hay un mirar hacia atrás para ir hacia adelante (Mamani 2007: 304), en un movimiento que podríamos llamar "en espiral". Me decía Fausto Vargas, dirigente quechua de Sucumbíos en el área educativa: "Tenemos el pasado presente. Tenemos que regresar hacia atrás para estar en el presente porque nos sirve mucho lo de ayer para hoy. Entonces, en este sentido es el espiral: salimos de nuestro interior y seguimos abriendo el espacio hacia atrás" (Entrevista realizada por el autor, Quito 2009).

Esta dinámica marca también la dinámica política dirigentes/comunidades porque para avanzar hay que volver a las bases, como me refería Rafael Guitarra, dirigente de Cotacachi (Entrevista realizada por el autor, Cotacachi 2009).

\section{UNA AGENDA DE DIÁLOGO}

ENTRE LOS MOVIMIENTOS INDÍGENAS Y EL MARXISMO

Se podría definir a la relación entre el marxismo y los movimientos indígenas en América Latina por dos características: es problemática y, a la vez, es fecunda, tanto en lo político como en lo epistémico. Al evaluar su fecundidad tengo en cuenta sobre todo la potencialidad revolucionaria, en los dos sentidos. 
Para continuar en el "espíritu de Mariátegui" es fundamental que esto se aborde desde la praxis de lucha política en alguna forma de articulación o comunicación mutua, y que la reflexión sobre esa praxis pueda hacerse en un ejercicio de diálogo de saberes como espacio de abordaje de los aspectos problemáticos y de crecimiento de los elementos de fecundidad, separables solamente en un nivel analítico.

El Amauta testimonia este camino cuando expresa que en la búsqueda del socialismo aprendió a valorar y entender lo indígena: "Confieso haber llegado a la comprensión, al entendimiento del valor y el sentido de lo indígena, en nuestro tiempo, no por el camino de la erudición libresca, ni de la intuición estética, ni siquiera de la especulación teórica, sino por el camino -a la vez intelectual, sentimental y práctico-, del socialismo" (Mariátegui 2010b: 244).

Los movimientos indígenas han hecho, en general, una opción política por priorizar su propia base y sus propios espacios tanto de praxis como de reflexión. Esto debe ser claramente respetado si no se quieren repetir errores pasados y si se quiere realizar un diálogo de saberes profundo, que tenga como primer gran elemento base al respeto. La riqueza de este diálogo puede potenciar la construcción epistémico-política indígena y, a la vez, puede servir en la necesaria resignificación descolonizada y latinoamericanizada de los contenidos marxianos. Mariátegui marca una línea clave en estos dos sentidos.

El marxismo necesita de muchos elementos que los planteos indígenas le pueden aportar, sobre todo, depurarse de interpretaciones que lo traban en dos líneas: en su articulación con lo latinoamericano y en el debilitamiento de su potencialidad revolucionaria, las cuales muchas veces coinciden. Recordemos que Mariátegui (2005: 378) sostenía que "nuestro socialismo" no "sería ni siquiera socialismo, si no se solidarizase primeramente con las reivindicaciones indígenas".

Algunos de estos elementos son:

1) La crítica a la matriz moderna y eurocéntrica que está en la base de muchos elementos de la caracterización del socialismo; 
2) Cierta tendencia al dogmatismo que supera o entorpece el análisis de la realidad latinoamericana; Mariátegui (2005: 331) sostenía que los que "han continuado" el "espíritu" de Marx "han sido, más bien los revolucionarios, tachados de herejía, que han osado enriquecer y desarrollar las consecuencias de la idea marxista". Fernández Díaz (1991: 137-138) destaca, en Mariátegui, la utilización de la "pareja conceptual" compuesta por "herejía/ dogma" especialmente utilizado en su obra Defensa del marxismo.

3) La propensión a adherirse a "filosofías de la historia" con características teleológicas, cerradas, hegelianas, ligadas a una base evolucionista y determinista (Löwy 2001; Tarcus 2008), aspecto marcado fuertemente por Mariátegui (Kaysel 2014: 238).

4) La necesidad de superar definitivamente ese empobrecimiento esquemático (Aricó 1998: 161-162) que organiza la historia en etapas universales y que tiende a una teoría de la necesidad del proceso histórico único bajo un esquema unilineal (Del Barco 1965: 96).

5) La superación de cualquier esperanza de una etapa capitalista como previa al socialismo y en el supuesto papel positivo de algún tipo de burguesía; Mariátegui (2005: 405) no tenía expectativas en ese sentido porque "no existe en el Perú, como no ha existido nunca, una burguesía progresista, con sentido nacional, que se profese liberal y democrática y que inspira su política en los postulados de su doctrina".

6) La vinculación a una lectura "feudalista" de la realidad agraria en América Latina que ha tenido como consecuencia la desviación de la centralidad de la lucha anticapitalista y que muchas veces se expresa en un planteo descampesinizador.

7) La superación de la ligazón de una postura de izquierda con una postura "progresista" muchas veces coherente con una concepción naturalista que combina malamente a Marx con Darwin (Balibar 2006: 96) y que establece una confusa y sospechosa base común con la derecha procapitalista en cuanto a la percepción espacio-temporal.

8) En esta misma línea, la superación de cualquier valoración despectiva de la capacidad revolucionaria del campesinado y del movimiento indígena.

9) El reconocimiento del carácter "tensionado" de la obra marxiana (Löwy 2001; Tarcus 2008: 27; Lander 2006: 216; Balibar, 2006: 102; Dussel 1990: 26; Aricó 1998: 238).

Para el movimiento indígena, este diálogo de saberes con el marxismo podría ser una ocasión de profundizar un elemento clave de su emer- 
gencia como sujeto político y revolucionario en la región: la politización de lo étnico.

Algunos temas que pueden dar una idea de una posible agenda de este diálogo pueden ser:

1) El cuestionamiento sobre el lugar epistemológico desde el cual se construye el conocimiento. Reubicar claramente este lugar en la praxis de la lucha popular latinoamericana, y especialmente en la indígena, teniendo en cuenta que su carácter ancestral es un aporte fundamental. Una lucha popular que no sólo abarca sus expresiones políticas más notorias sino la constante lucha por la vida (desde las movilizaciones más amplias hasta la lucha cotidiana en cada familia y comunidad). Esto significa negarse al eurocentrismo y a cualquier determinismo científico-técnico en la lectura de nuestra realidad latinoamericana, emanciparse de las filosofías productivistas-progresistas y recuperar al marxismo como "Ciencia de la Revolución" (Shanin 1990: 306). Implica una lectura "desde abajo" que contradiga cualquier construcción de elitismo vanguardista y se adentre en la búsqueda popular y cotidiana de resistencia, de creación de alternativas que nuestros pueblos han producido ancestralmente y producen día a día. Recordemos que para Mariátegui "había una necesidad acuciante de un socialismo práctico - que surgiese de la práctica diaria de las clases subalternas-que cambiase la sociedad" (Munck 2017: 99).

2) Unido profundamente a esto, y a una revisión del concepto de proletariado en la línea expuesta más arriba, considerándolo como sujeto político y epistémico, la búsqueda de este "lugar" desde donde producir conocimiento revolucionario, liberador y descolonizador, es fundamental para una "ciencia de la Revolución" verdaderamente popular.

3) Desde la comprensión comunitaria y de reciprocidad del mundo indígena se hace necesario un diálogo acerca de la concepción del hombre como "ser relacional" y de su "esencia comunitaria" con la cual se reconciliaría a través del comunismo y que lo reconcilia también con su propio trabajo y con la naturaleza. Esta concepción es coherente con la fundamentación de la "práctica revolucionaria" y con la reciprocidad persona-colectivo que la nutre (Balibar 2008: 20.134).

4) Un diálogo entre el planteo indígena que ha sido caracterizado como "paradigma biocéntrico" y con la idea práxica de "crianza de la vida" enlazando el planteo del Buen Vivir con los conceptos marxistas de "producción de la vida" y de la naturaleza como "ser orgánico del hombre". Elementos que puedan ayudar a liberar al marxismo de la separación moderna entre 
hombre y naturaleza desde el pensamiento indígena. Aquí hay interesantes aportes del ecosocialismo.

5) La discusión sobre el concepto de propiedad en el contexto del planteo indígena de "pertenencia a la Pachamama". Aquí entraría la distinción marxiana entre propiedad y posesión como uno de los elementos del diálogo y el análisis del relacionamiento con la tierra desde las cosmovisiones indígenas con un rechazo claro al concepto de propiedad privada.

6) Unido a esto la profundización en la valoración del comunismo primitivo en el planteo marxiano y la relación con el comunismo indígena. No olvidemos lo que decía Mariátegui (2005: 452) "El socialismo está en la tradición americana, la más avanzada organización comunista, primitiva, que registra la historia, es la incaica". Aquí es clave la atención al valor revolucionario de las comunidades rurales y específicamente las indígenas. La relación con el planteo del último Marx es clave. Estudiar el porqué y el contenido del acercamiento de Marx a los narodniki que tendría que ver con su desprecio cada vez mayor a la sociedad capitalista (Hobsbawm 1971: 36).

7) La relación entre praxis revolucionaria y la subjetividad / ética / espiritualidad en el materialismo. Esto teniendo en cuenta los planteos de Mariátegui sobre el "Alma Matinal" - y del Che Guevara sobre el "Hombre Nuevo" - y las espiritualidades indígenas. Esto exige una profundización y revisión del tema del materialismo, liberarlo de todo sentido naturalista y positivista y recuperar el potencial creativo de la concepción materialista de la historia (Tarcus 2008: 30). Hay que tener en cuenta que este tema provocó dificultades a veces muy serias entre movimientos indígenas y marxistas.

8) El análisis de las formas de organización política y económica del mundo indígena sin aplicaciones de modelos y tipificaciones eurocéntricas. En esto profundizar en la relación entre Tawantinsuyo y socialismo es un tema que hay que seguir trabajando. En este sentido vale la pena ahondar en el análisis del concepto de Modo de Producción Asiático o Peruano en el contexto de los planteos descolonizadores, continuando la importancia de la ruptura con la unilinearidad histórica ligada al análisis occidental; como modo no occidental de organización que puede brindar elementos para análisis conjuntos en el Sur político; en la relación con el modo comunitario y su supervivencia junto a la perdurabilidad de formas de propiedad colectiva; en la relación "Estado-comunidades"; como alternativa crítica a la lectura feudal de la estructuración agraria; analizando la predominancia de producción de valores de uso con relativización de la moneda. Aquí hay aportes interesantes de García Linera (2009: 237). 
9) La revisión del concepto de Socialismo y del camino hacia él desde las experiencias latinoamericanas, tener fuertemente en cuenta lo planteado por Mariátegui, especialmente sobre el papel del mundo indígena en estos temas.

10) La revisión de algunas caracterizaciones de Marx en cuanto a considerarlo "moderno" y en su relación con el fenómeno colonial. Es clave aquí la crítica epistemológico-política a la modernidad en cuanto capitalista (Lander 2006: 222-223). También la crítica a las nociones que se definen en torno a las filosofías del "progreso". Las críticas a las mismas de Benjamin y Gramsci -ambos lectores de Sorel- pueden aportar a esta problemática (Tarcus 2008: 16), sobre todo relacionándolas a las elaboraciones ligadas a los movimientos indígenas que se produjeron en este sentido en nuestra región.

11) El tema de la espacio-temporalidad, planteando un diálogo entre la dialéctica marxista -en cuanto crítica y abierta - como dinámica histórica y la temporalidad "en espiral" del mundo indígena y a la idea andina de unión de opuestos complementarios. Mariátegui planteó elementos para esta revisión sobre todo desde su recuperación revolucionaria de la tradición. ${ }^{3}$

12) La relación entre el concepto de "totalidad" en la comprensión marxiana y del sentido "holístico" propia de las cosmovisiones indígenas. Un aporte interesante a tener en cuenta aquí son los planteos de Dussel (1974) con respecto a la analéctica y la exterioridad, y también la contundente crítica indígena a la compartimentación del conocimiento - que puede relacionarse profundamente con la marxiana- en la línea de una confrontación con el pensamiento hegemónico funcional al capitalismo (Veltmeyer 2006: 12).

En este diálogo es bueno tener en cuenta lo que expresaba Florestan Fernandes (1995: 17): "Veo en Mariátegui el intelectual marxista más puro y apto para percibir lo que sucedió; y, si estuviese vivo, para trazar los caminos de superación que relacionan dialécticamente la tercera revolución capitalista a la plenitud madura del marxismo revolucionario". ${ }^{4}$

3 "la tradición, en cambio, está viviente porque yace en un tiempo que es el eterno presente del mito, esto es, en un hecho absolutamente novedoso que sin embargo se comunica con un tiempo originario" (Terán 2008: 176).

4 El texto original en portugués dice: "Vejo em Mariátegui o intelectual marxista mais puro e apto para perceber o que sucedeu; e, se estivesse vivo, para traçar os caminhos 
Así, en la línea de Mariátegui, que realiza esa "síntesis fascinante" entre el marxismo y la realidad indígena (Vanden y Becker 2013: 19), es importante que el marxismo siga depurándose de todo rasgo de eurocentrismo. Como recuerda Löwy (2007: 10) "fue el eurocentrismo, más que cualquier otra tendencia, el que devastó el marxismo latinoamericano" (Melis 1996: 15).

También es importante que evite un marxismo "cerrado" (Vanden y Becker 2013: 30); renegando del "progresismo" en cuanto emparentado a la espacio-temporalidad evolucionista y capitalista y al etapismo de la Segunda Internacional (Terán 2008: 181); realizar "el rechazo de una etapa capitalista como pasaje necesario para los países latinoamericanos" (Melis 1976: 126). Mariátegui (2010b: 305) decía que "el advenimiento político del socialismo no presupone el cumplimiento perfecto y exacto de la etapa económica liberal, según un itinerario universal".

Su convicción era clara: los progresos del capitalismo redundan en un aumento geométrico de la barbarie. Esa realidad siempre fue subestimada desde una perspectiva eurocéntrica. Un marxista peruano, en cambio, no tiene por qué engañarse al respecto. Basta mirar para atrás o para el presente. Éxitos y progresos traen consigo contradicciones crecientes - en el extremo fatal implosivas-. Una civilización que reposa en la riqueza, en la grandeza y en el poder por cualquier medio exige un sistema social de exclusión, opresión y represión. Ella puede mantenerse y reproducirse liberando sus potencialidades fascistas y racistas, o sea, la devastación de la naturaleza, de la humanidad y de la cultura. Es su estructura, funcionamiento y ritmos históricos que arruinan su sostenimiento y su continuidad (Fernandes 1995: 16). ${ }^{6}$

de superação que ligam dialeticamente a terceira revolução capitalista à plenitude madura do marxismo revolucionário" (traducción del autor).

5 Mariátegui (2010a: 42) dice que en la época pre-bélica había "un respeto supersticioso por la idea del progreso. La humanidad parecía haber hallado una vía definitiva. Conservadores y revolucionarios aceptaban prácticamente las consecuencias de la tesis evolucionista. Unos y otros coincidían en la misma adhesión a la idea del progreso [...] chata y cómoda filosofía".

6 El texto original en portugués dice: "Sua convicção era clara: os progressos do capitalismo redundam em aumento geométrico da barbárie. Essa realidade sempre 
Esta base en las condiciones reales de la praxis de lucha popular para construir conocimiento implica también un "tipo de intelectual": un intelectual militante que priorice su aporte a los procesos revolucionarios sobre cualquier condicionamiento de adscripción teórica. Mariátegui es un "marxista convicto y confeso", pero es, sobre todo, un revolucionario (Melis 1976: 132). La clave de su ser revolucionario la encontró en un mundo - como el indígena- que, despreciado muchas veces hasta por sus compañeros de izquierda, contenía y contiene una potentísima alternativa que puede enriquecer e impulsar la superación del capitalismo en América Latina.

\section{CONSIDERACIONES FINALES}

Hay una conexión en puntos centrales entre la propuesta mariateguiana y la del Buen Vivir.

Frente al evidente nuevo fracaso del neoliberalismo en la región es indispensable profundizar en el diálogo entre las propuestas teóricas y prácticas de los planteos alternativos que pretenden responder a las mayorías populares.

Además, queda evidenciado que las propuestas indígenas - como lo había captado Mariátegui- son un elemento clave para una relectura latinoamericana del planteo marxiano que puede dar así una inmensa riqueza al análisis de la región y puede encontrar formas de una relectura profunda, en gran parte inédita.

foi subestimada de uma perspectiva eurocêntrica. Um marxista peruano, todavia, não tem por que enganar-se a respeito. Basta olhar para trás ou para o presente. Exitos e progressos trazem consigo contradições crescentes - no extremo fatal implosivas. Uma civilização que repousa na riqueza, na grandeza e no poder por quaisquer meios exige um sistema social de exclusão, opressão e repressão. Ela pode manter-se e reproduzir-se liberando suas potencialidades fascistas e racistas, ou seja, a devastação da natureza, da humanidade e da cultura. É sua estrutura, funcionamento e ritmos históricos que arruínam seus alicerces e sua continuidade" (traducción del autor). 
Esta relectura descolonizadora desde América Latina puede servir también para otras regiones del Sur político y, por eso, para el llamado Diálogo Sur-Sur.

\section{BIBLIOGRAFÍA}

ARICó, José. Marx y América Latina. Buenos Aires: Catálogos, 1998.

BALIBAR, ETIENNE. La filosofía de Marx. Buenos Aires: Nueva Visión, 2006. BARCO, OSCAR DeL. "Las formaciones económicas precapitalistas de Karl Marx". Pasado y Presente 9 (1965): 84-106.

CoORdinadora ANDina de ORGANIZACIONES IndíGENAS (CAOI). Buen Vivir / Vivir Bien. Filosofía, políticas, estrategias y experiencias regionales andinas. Lima: CAOI/Oxfam América/SAL, 2010.

DusSEL, ENRIQuE. El último Marx (1863-1882) y la liberación latinoamericana. Un comentario a la tercera y cuarta redacción de "El Capital”. México: Siglo XXI, 1990. - Ética comunitaria. Florida: Paulinas, 1986. - Introducción a la Filosofía de la Liberación Latinoamericana. México: Extemporáneos, 1977.

Ágora, 1974.

Fernandes, Florestan. "Significado atual de José Carlos Mariátegui". Principios 35 (1995): 16-22.

Fernández DíAz, Osvaldo. "Gramsci y Mariátegui: frente a la ortodoxia". Nueva Sociedad. 115 (1991): 135-144.

FloReS Galindo, AlBerTo. Obras completas. Lima: Sur, 2008.

GARCÍA LINERA, ÁLVARO. Forma valor y forma comunidad: aproximación teórica-abstracta a los fundamentos civilizatorios que preceden al Ayllu Universal. La Paz: Clacso/Muela del Diablo/Comuna, 2009.

GERMANÁ, CÉSAR. El "socialismo indo-americano" de José Carlos Mariátegui: Proyecto de reconstitución del sentido bistórico de la sociedad peruana. Lima: Amauta, 1995. 
HOBSBAWm, ERIC. "Introducción". Formaciones económicas precapitalistas. Córdoba: Cuadernos de Pasado y Presente, 1971. 5-47.

INUCA LECHÓN, JoSÉ BENJAMÍN. Yachay tinkuy o encuentro y confrontación de saberes: genealogía de la interculturalidad y del buen vivir en la educación de los pueblos kichwas del Ecuador desde mediados del siglo XX. Tesis de doctorado. Quito. Flacso, 2017.

KAYSEL, ANDRÉ. Entre a nação e a revolução: o marxismo de matriz comunista e o nacionalismo popular no Peru e no Brasil (1928-1964). Tesis de doctorado. São Paulo: Universidade de São Paulo, 2014.

KowII, ARIRUMA. "El Sumak Kawsay". Sumak Kawsay Yuyay. Antología del pensamiento indígena ecuatoriano sobre Sumak Kawsay. Antonio L. Hidalgo Capitán, Alejandro Guillén García y Nancy Deleg Guazha (eds.) Huelva: FICUHU, 2014. 159-168.

LANDER, ERNESTO. "Marxismo, eurocentrismo y colonialismo". La teoría marxista hoy. Problemas y perspectivas. Atilio Borón, J. Amadeo y S. González (comps.). Buenos Aires: Clacso, 2006. 209-243.

LÖWY, MiCHEL. El marxismo en América Latina. Santiago de Chile: LOM, 2007.

. (2001). "Historia abierta y dialéctica del progreso en Marx". Artículo en línea disponible en http://www.fundanin.org/lowy4.htm.

LLASAG FERNÁNDEZ, Raúl. "El Sumak Kawsay y sus restricciones constitucionales". Foro. Revista de Derecho 12 (2009): 113-125.

MACAS, LuIS. "Sumak Kawsay. La vida en plenitud". Sumak Kawsay Yuyay. Antología del pensamiento indígena ecuatoriano. Antonio L. Hidalgo Capitán, Alejandro Guillén García y Nancy Deleg Guazha (eds.). Huelva: FICUHU, 2014. 169-178.

MAMANI CONDORí, CaRLOS. "Memoria y reconstitución". Intelectuales indígenas piensan América Latina. Claudia Zapata Silva (comp.). Quito: Universidad Andina Simón Bolívar/Abya Yala/CECLA, 2007. 285-310.

Mariátegui, José Carlos. Defensa del marxismo y otros escritos. Caracas: El perro y la rana, 2017.

. El Alma Matinal y otras estaciones del hombre de boy y el artista y la época. Caracas: El perro y la rana, 2010a. 
2010b.

Ideología política y otros escritos. Caracas: El perro y la rana, . Invitación a la vida heroica. Lima: Fondo Editorial del Congreso del Perú, 2005.

MAZzeO, Miguel. Invitación al descubrimiento. José Carlos Mariátegui y el socialismo de Nuestra América. Buenos Aires: El Colectivo, 2009. Melis, ANTONIO. "El debate sobre Mariátegui: resultados y problemas". Revista de Crítica Literaria Latinoamericana 2. 4 (1976): 123-132. . "José Carlos Mariátegui hacia el siglo XXI". Cuadernos de reciénvenido 1 (1996): 5-29.

. "Mariátegui e a crítica da vida cotidiana". Lutas Sociais 17. 30 (2013): 63-75.

MuncK, RonaLDO. "Repensando América Latina. ¿Regresando al futuro?". Latin American Perspectives en Español y Portugués 1: buscando alternativas políticas y económicas. Claudio Katz et al. Buenos Aires: Clacso; Riverside: Latin American Perspectives, 2017. 93-118.

QujJano, ANíBAL. "Colonialidad del poder, eurocentrismo y América Latina". Ernesto Lander (comp.). La colonialidad del saber, eurocentrismo y ciencias sociales. Perspectivas latinoamericanas. Buenos Aires: Clacso, 2000. 201-248.

Cuestiones y horizontes: de la dependencia bistórico-estructural a la colonialidad/descolonialidad del poder. Buenos Aires: Clacso, 2014.

- Des/colonialidad y bien vivir. Un nuevo debate en América

Latina. Lima: Universidad Ricardo Palma, 2014.

SHANin, TEOdOR. El Marx tardio y la vía rusa. Marx y la periferia del capitalismo. Madrid: Revolución, 1990.

Stavenhagen, Rodolfo. Las clases sociales en las sociedades agrarias. México: Siglo XXI, 1996.

TARCus, HoraCiO. "¿Es el marxismo una filosofía de la historia? Marx, la Teoría del Progreso y la 'Cuestión Rusa". Andamios. Revista de Investigación Social 8 (2008): 7-32. 
TERÁN, OSCAR. "Amauta: vanguardia y revolución". Prismas. Revista de bistoria intelectual 12 (2008): 173-189.

Tible, Jean. "José Carlos Mariátegui: Marx e América Indígena". Cadernos Cemarx 6 (2009): 97-114.

VANDEn, HARRY E. y MARC BeCKer. "L'Amauta: la vie et l'œuvre de José Carlos Mariátegui". Indianisme et paysannerie en Amerique latine. Socialisme et libération nationale. José Carlos Mariátegui y Álvaro García Linera, París: Syllepse, 2013. 13-32.

VeltMeyer, Henry. "El proyecto post-marxista: aporte y crítica a Ernesto Laclau". Revista Theomai. Estudios sobre Sociedad, Naturaleza y Desarrollo 14 (2006). 